\title{
Institutional classification factors research strategy of Saudi Arabia University ranking
}

\author{
Ibrahim M Alarif ${ }^{1,2 *}$ \\ ${ }^{1}$ Department of Mechanical and Industrial Engineering, College of Engineering, Majmaah University, Al Majmaah 11952, Riyadh, Saudi Arabia \\ ${ }^{2}$ Engineering and Applied Science Research Center, Majmaah University, Al-Majmaah 11952, Riyadh, Saudi Arabia
}

\begin{abstract}
This project presents an investigation of Institutional classification factors of Majmaah University ranking in the areas of economic, social, academic-corporate collaboration, and quality control. The process of article collection considered articles written on a specific research problem. Several categories emerged. The categories selected included engineering, energy, environmental science, agricultural, biochemistry, medicine, pharmacology, computer science, mathematics, physics and astronomy, chemistry, chemical engineering, material science, and others. 96,000 topics in SciVal have been identified by scrutinizing citation links between materials in Scopus. The results show that Majmaah University has made efforts to increase citations and visibility of academic publications. Majmaah University is engaged in a range of collaboration with the corporate sector in areas such as consultation, examination, scholarships and prizes, preparation, and the development of industrial recommended boards. The results also show that Majmaah University has made efforts to increase citations and visibility of academic publications, particularly in areas that are underrepresented in the relevant databases such as engineering. The report shows that the university's programs fulfill all the criteria of ABET and NCAAA accreditation. Overall, Majmaah University ranks low in research institutional ranking compared to King Saud University and King Abdulaziz University, Harvard University, and Massachusetts University.
\end{abstract}

\section{Introduction}

\section{Literature review}

The significance of higher education has been recognized through the preparation of skillful specialists considered to be the key force for the development of countries. Higher education is critical in modern market-based economies. Specifically, higher education promotes the growth and maintenance of the knowledge obtained by the youth. Higher education is the basis of human capital development, which can later act as a critical aspect of growth. The current state of higher education institutions in countries must reflect market needs and benchmarks set by the world's top institutions. As such, institutions use classifications to evaluate their performance compared to other comparable universities. Rankings have specific impacts on highly ranked institutions, established institutions, high-achieving students or scholars, and internationally mobile students.

Different institutional classification factors are utilized in the ranking of universities. The ranking influences the prestige that institutions carry as well demand from students as well as funding for research-related projects as well as academic publication practices, procedure, and governance of higher education associations, legitimacy of higher education associations, reputation, higher education marketing, recruitment, and admission. World-class institutions attract the attention of top students and academicians and offer them excellent learning and teaching environment with the necessary facilities available [1]. Therefore, universities are creating a strength to achieve a world-class university title. The increasing expansion and importance of world-class institutions is the main reason why universities are in a global race to establish world-class institutions. Mainly, universities are ranked according to research publications and teaching excellence at both national and international levels.
Rankings also enable universities to appreciate a high level of acceptance by the broader public and among stakeholders. While the data collection process and ranking methodology may be sophisticated, it allows users to select choices for comparison. In many cases, institutions are ranked based on the scores earned according to the criteria used by ranking providers. Many global university rankings have become multidimensional and interactive in the past years, and users can customize authoritative tables. In other cases, institutions may use different ranking criteria and, as such, gain different positions. In addition to features introduced to the global ranking, similar methodologies or adjusted methodologies may be used to account for differences in disciplines, countries, world regions, age of institutions, and subjects [2]. Therefore, classification and ranking tools are essential for comparing institutions, albeit for different purposes. Classification is closely intertwined with ranking. Classification focuses on establishing similarities rather than ordering institutions. It is linked intertwined with ranking through procedures, structure, content, and how it is used and understood by users, stakeholders, institutional leaders, policymakers, and researchers [3]. It is for this reason that there are best practices, protocols, and standards established for ranking systems and classification. The impacts of ranking on higher education institutions should not be underestimated.

${ }^{\star}$ Correspondence to: Ibrahim M Alarifi, Department of Mechanical and Industrial Engineering, College of Engineering, Majmaah University, Al Majmaah 11952, Riyadh, Saudi Arabia, Engineering and Applied Science Research Center, Majmaah University, Al-Majmaah 11952, Riyadh, Saudi Arabia, E-mail: i.alarifi@mu.edu.sa

Key words: SciVal, scopus, ABET, research Strategy, NCAAA, QS Rankings

Received: March 07, 2020; Accepted: May 19, 2020; Published: May 23, 2020 
Academic publication practice is one of the institutional classification factors that are widely used. Citation indices and publication volumes account for a significant weight in the overall weighting of the global university rankings. As a result, academics have been encouraged to publish high-impact journals indexed by data brokers that support rankings and introduce measures that improve the visibility of publications in order to attract academic, social networks, use of research information tools, and to attract more citations open access to research outputs.

There are numerous efforts to increase citations and visibility of academic publications by Saudi Arabia Universities. The trend has had a positive impact on the restrictive recognition of journals in specific databases and the spread of knowledge. Universities are continually feeding their data into areas that are underrepresented in the relevant databases such as niche and young disciplines that traditionally favor book publications as compared to journal articles. On the other hand, the focus on journals indexed by specific databases and high-impact journals can skew the choice of research methodologies, favor English over other languages, and favor theory over practical relevance. According to Douglass et al. [4], if universities focus on improving ranking positions rather than improving on accrual quality of research, the real quality of university education may suffer.

The current ranking of Saudi universities can be accessed online. Locally, the top ten universities are King Saud University, King Abdulaziz University, King Abdulla University of Science \& Technology, King Fahd University of Petroleum \& Minerals, Umm Al Qura University, King Faisal University, King Khalid University, Al-Imam Muhammad Ibn Saud Islamic University, Taibah University and Tabuk University in that order. In the world rank, King Saud University, King Abdulaziz University, and King Abdulla University of Science \& Technology rank 451, 437, and 494, respectively. Over 63 Universities in Saudi Arabia are included in the rank. Majmaah University ranks 4782 in the world ranking and 22nd among Saudi Arabia Universities [5].

Academies production a significant role in innovation, economy, and other areas of society. As such, there has been a pressing need for quality improvement initiatives and outcome studies in the research enterprise. Every year, local and international universities publish yearly results of their ranking [6]. Whether it is QS Rankings, Academic Ranking of World Universities, and World University classifications or other local classifications, the results attract the attention of scholars. Institutions consider a range of dimensions of academic quality including research and development capability, number of international students, the employment rate of graduates, the expertise of faculty, satisfaction of students, student excellence, alumni giving, financial resources, expert opinion, faculty resources, social mobility, graduation rate performance, graduation, and retention. The indicators comprise of input measures that reflect the quality of faculty, students, and other resources used in education while the outcome measures capture the results of the education that students receive.

Normalized scores for every measure are weighted to come up with the final score. The institutional classification factors between universities are inconsistent. Many institutions rely on the ranking system as an indicator of improvement in comparison with other universities. The ranking system can also be used for a cost-benefit analysis to support additional funding requests and for previous funded initiatives. Additionally, the rankings can be used by consumers to examine higher education chances both internationally and nationally. Earlier studies on university ranking have established that emphasis on institutional resources and reputation may not accurately correspond to quality [7]. Commonly suggested academic quality indicators include higher degrees, professional training, and percentage of graduates entering employment upon graduation, program completion rates, and student entry criteria. Citations and publications have also been assessed for suitability as measures of an institution's worth. Overall, the use of multiple criteria when assessing institutions for a choice of career decisions and quality has been identified to be a best practice approach.

The assessment of research as an academic quality indicator in the institutional ranking is largely unexplored. The assessment of institutional classification factors in Saudi Arabia is unexplored. While associations have an obligation to make certain that outcomes and research procedure prudently and effectively manage resources, institutional classification evaluation that involves a comparison between institutions is not common. Administrators and institutions need reliable evaluation indicators of academic quality and research. University rankings are often used for this objective. Concerns over the impacts and reproducibility of research in Saudi Arabia call for initiatives to identify and compare institutional classification factors used by specific Universities in order to measures academic and research performance [8]. The purpose of this report is to assess factors in institutional classification as used by Saudi Arabia Universities.

The challenges and motivation of this study on Institutional classification factors is to examine the utilization of ranking techniques from both academic and research perspectives across a systematic review of visibly accessible university ranking systems. Articles focused on a common intellectual research problem will be used. 96,000 topics in SciVal have been created by analyzing citation links between articles in Scopus. The novel works are identifying and comparing institutional classification factors locally and internationally and it used by specific Universities in order to measures academic and research performance.

The process of article collection considered articles written on a specific research problem. Several categories emerged. The categories selected included engineering, energy, environmental science, agricultural, biochemistry, medicine, pharmacology, computer science, mathematics, physics and astronomy, chemistry, chemical engineering, material science, and others. 96,000 topics in SciVal have been identified by scrutinizing citation links between materials in Scopus. As a result, a strong link between topics has been formed. Figure 1 shows the histogram topics with a high prominence percentile in which Majmaah University is contributing.

\section{Investigating institutional benchmarking universities}

Benchmarking involves the systematic evaluation and comparison of results, processes, and practices in order to support self-regulation and improvements. Majmaah University is a supplier of knowledge workforce for economies. The tough competition in the labor market also means that there is a higher demand for higher education. As a result, a growth in demand to build and diversify the popularity of world-class universities has been recorded. The increasing importance of world-class universities can be explained in terms of social growth and contribution to the economic growth of countries. It is for this reason that nations are in a global race to build world-class universities. Such universities attract the attention of top students and academicians while offering learning and teaching environment with the availability of essential skills. Universities are often ranked according to their research publications and teaching excellence at both the international and national levels. Consequently, it is common practice for different universities to compete by benchmarking diverse indicators of top universities. 
The rankings of the institutions are major performance indicators of institutions. Table 1 shows the evaluation of an institution's performance is of critical importance institutional research formulate the existing rankings and the breakdown of measuring the performance such, the scholarly output, citation and number of authors. Each factor indicates the strength and the performance in research for each the university. Learning from and sharing good practices of foreign institutions are regarded as benchmarking. Benchmarking is an essential element of ongoing learning [9]. Specifically, in the case of higher education, the practice involves looking for the practices of best institutions that will influence the achievement of the superior performance goals. Studies show that benchmarking ensures superior performance of institutions. Study results also show that knowledge creation is an essential area in the context of higher education.

\section{The research factors}

In the context of knowledge creation, universities are a focus on the improvement of research capabilities in publications top percentiles in journal and citations as shown Table 2. The rise in the adoption of evidence-based decision-making has been accompanied by the need for more research in diverse areas of interest. Benchmarking enables the structured sharing of good practices and ideas on institutional weaknesses and strength Information on institutional quality and

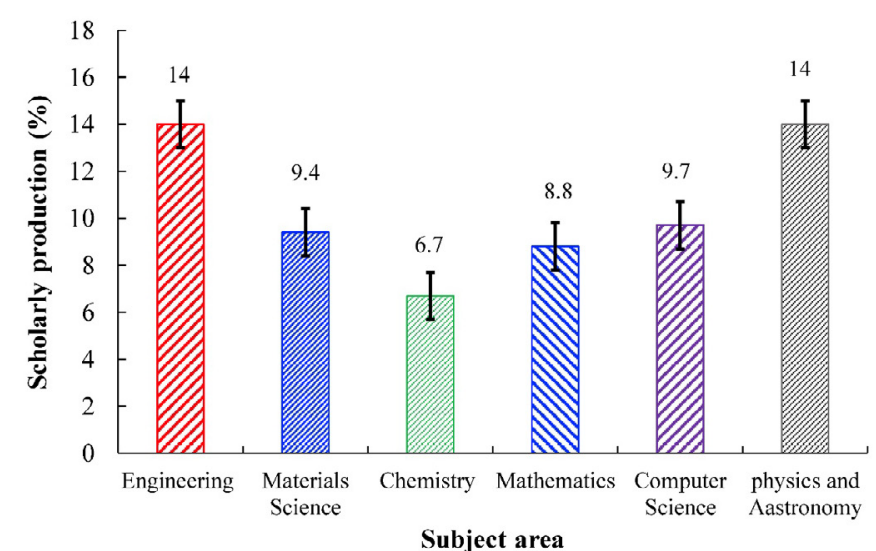

Figure 1. Some subject area research performance of Majmaah University from 2015 to 2019 performance of the internationalization process is turned into new opportunities for strategic developments of universities. Due to the importance of research, the research factor is one of the considerations that research institutions take into consideration during benchmarking. Learners in universities that score highly in research likely have professors who are renowned in their field. Professors in these institutions have published in academic journals.

Majmaah University understands research as an essential factor in the progress and development due to its contribution to spreading concepts of creativity and innovation as well as presenting solutions to problems facing society. The relatively young university operates through research groups such as the artificial intelligence group, information security group, multimedia security, and image processing research group. Each group has research priorities that guide its research activities. For example, the Artificial Intelligence Group (AIG) functions under the Computer Science department and Information at Majmaah Universities of Science-Zulfi College. The group focuses on subjects in areas of image processing, data mining, and pattern recognition. The group has carried out cutting edge research on Smart devices and machine learning, big data analytics, document analysis and recognition, spatial image analysis and recognition, medical data and image analysis for better disease control and diagnosis, prediction of solar sun and weather conditions, pattern recognition for effective e-learning, and Arabic language character recognition [10].

Accordingly, highly ranked institutions are likely to invest resources in improving their schools and advancing ideas in major fields of study. Universities conduct research into fields such as computer science, sociology, criminal justice, engineering, and medicine [11]. For students, research and development create opportunities to work with industry experts and professors. By conducting their own studies, students can earn publication and benefit exclusively from career opportunities, awards, and fellowships. Research and development are one of the major ways through which universities bridge the gap that exists between active student participation and the availability of information [12]. The research presents advantages for both the institutions and students as a whole. By publicizing their achievements, universities benefit from the positive reputation of academic departments, thus increasing opportunities and enrollment for grants. Given that many universities want to resemble the institutions at the top of the academic pecking order, they, therefore, become research-intensive.

Table 1. Institution Overall Research Performance from 2015 to 2019

\begin{tabular}{|c|c|c|c|}
\hline \multirow{2}{*}{ INSTITUTIONAL NAMES } & \multicolumn{3}{|c|}{ Institution Overall Research Performance } \\
\cline { 2 - 4 } & Scholarly Production & Citation & Citations per Publication \\
\hline King Saud University & 28,661 & 244,982 & 8.5 \\
\hline King Abdulaziz University & 28,018 & 438,916 & 15.7 \\
\hline Majmaah University & 1,292 & 6,911 & 5.3 \\
\hline Harvard University & 179,567 & $2,950,461$ & 1,664 \\
\hline Massachusetts Institute of Technology & 53,977 & 989,571 & 16.4 \\
\hline
\end{tabular}

Table 2. Publications top percentiles in journal and citations

\begin{tabular}{|c|c|c|c|c|c|c|c|c|}
\hline \multirow[t]{2}{*}{ INSTITUTIONAL NAMES } & \multicolumn{4}{|c|}{ Publications Top Journal Percentiles (\%) } & \multicolumn{4}{|c|}{$\begin{array}{l}\text { Outputs Top Citation } \\
\text { Percentiles (\%) }\end{array}$} \\
\hline & $1 \%$ & $5 \%$ & $10 \%$ & $25 \%$ & $1 \%$ & $5 \%$ & $10 \%$ & $25 \%$ \\
\hline King Saud University & 1.8 & 10.6 & 23.3 & 47.6 & 1.7 & 7 & 13.2 & 30.8 \\
\hline King Abdulaziz University & 3.8 & 18 & 33.6 & 56.2 & 4.2 & 13.4 & 21.4 & 41 \\
\hline Majmaah University & 0.6 & 7.2 & 21.8 & 42.5 & 2.3 & 8.6 & 13.9 & 30.7 \\
\hline Harvard University & 7.9 & 30.6 & 48.2 & 75.3 & 4 & 13.5 & 23.3 & 45.7 \\
\hline Massachusetts Institute of Technology & 9.3 & 35.8 & 53.6 & 76.2 & 4.5 & 16.3 & 26.7 & 48.5 \\
\hline
\end{tabular}


Figure 2 illustrates the citation index for each institution, the highest from intranational university is Harvard University and King Abdulaziz University respectively. Therefore, universities have been seen to have a research role. Further, the growing trend in doctoral education is characterized by the practice of dispensing traditional dissertations and replacing it with the requirement for students to publish research articles in academic journals, thus moving the evaluation responsibility from the institutional committees to journal reviewers and editors. Institutions promote the recovery in standing as evidence-based practice improvement in the academic and research conditions [13]. From the practice of the higher education system in the United States and other developed nations, research plays a critical role in the growth and progress of university ranking and excellence in teaching [14]. Saudi Arabia universities are increasingly paying attention to the development of research capability and research environment. The efforts are evidenced by the publications number and the faculty profile of academic staff members in different academic disciplines ranging from Economics to English studies [15]. Furthermore, the development of the research capabilities within higher institutions of learning has fueled innovation and entrepreneurship.

\section{The economic \& social factor}

Higher education plays an essential role in social and economic development. Universities are a focal point of knowledge and its application that make a significant contribution to increasing higher skills while fostering innovation and economic growth and development. As such, institutions such as Majmaah University address economic and social challenges. Academic research creates new knowledge, and local firms take up and utilize it effectively to derive benefits for the business and society [16]. Majmaah University engages with the broader community as part of its mission to contribute to the broader community's economic development. Around the world, institutions are doing this in a range of ways, including offering extension courses for the local communities and offering cultural amenities such as theaters and museums. Majmaah University acts as a powerful economic engine in the city.

Further, higher learning institutions contribute to the economy by developing a quality workforce that allows people to do well in



\section{h5-index}

Figure 2. The universities research performance h5-index from 2015 to 2019 the modern global economy. Majmaah University provides students with a range of programs aimed at preparing learners for diverse economic sectors, thus helping them to succeed and grow in the labor market while keeping pace with changes in the innovation process and changes in the global economy. Institutions of higher learning promote lifelong learning while offering the opportunity to attract and engage in professional development and training [17]. Participating in programs broadens student skills. Therefore, universities help tackle skills mismatch. It is for this reason that university education is seen to be relevant. Individuals who take part in well-managed university programs do provide not only good services but also make better job creators and more employable.

More importantly, higher education is an innovation and technology driver. A mission of Majmaah University and other modern universities is to find solutions to challenges by conducting studies within global priority areas, contributing to production or resources, and social outcomes such as social engagement and health. Often, technologies designed can result in new products and advanced technology for use [18]. Given that knowledge is the true basis of higher education, its acquisition, transmission, and production through research translates to improvements in diverse facets of the economy. Hence, excellence has remained a major objective of higher education, including Majmaah University. Majmaah University retains universities' traditional role as producers of knowledge and critics of the society. Learners with training impart the economy, thus strengthening the bedrock upon which countries are built.

\section{Academic-corporate collaboration factor}

Academic-corporate collaboration involves partnerships that characterize academic and corporate affiliations. It indicates the percentage and number of outputs that have been co-authored by researchers from both corporate and academic affiliations. Scopus assigns an organization type upon which the collaborating institution is based [19]. The academic-corporate collaboration metrics are useful in investigating the working together of corporate and academic sectors as well as benchmarking cross-sector collaboration between researchers of similar disciplines and fields [20]. Academic-Corporate Collaboration Impact shows the citation impact of publications with or without corporate and academic affiliations. The impact metrics are essential for benchmarking the influence of publications with or without the academic-corporate partnership and to evaluate the collaborative citation impact of researchers in similar disciplines or fields. It can also identify benefits stemming from creating and maintaining academiccorporate collaborations. SciVal is used as a common tool for calculating academic-corporate Impact.

Table 3 shows the academic-corporate collaborations are critical as when universities focus on new knowledge and education; corporate provide a bridge to help transform new breakthrough into things that can actually be used. When new innovations come out from the academic bubble, innovation technologies flourish. There has been considerable growth in the collaborations between universities and companies. Firms that have been looking to reduce their spending on early research often turn to universities to perform research due to the access to the best minds in particular domains as well as resources such as laboratories [21]. On the other hand, universities have been more receptive due to the call to contribute more to local economies through research. Therefore, both sides are interested in forging long-term partnerships beyond a single one-off project. 
Table 3. Overall academic region and international collaboration growth

\begin{tabular}{|c|c|c|c|}
\hline $\begin{array}{c}\text { INSTITUTIONAL } \\
\text { NAMES }\end{array}$ & $\begin{array}{c}\text { Co-authors } \\
\text { (growth \%) }\end{array}$ & $\begin{array}{c}\text { Co-authored } \\
\text { publications } \\
\text { (growth \%) }\end{array}$ & $\begin{array}{c}\text { Field-Weighted } \\
\text { Citation Impact }\end{array}$ \\
\hline King Saud University & 4.3 & 35 & 1.4 \\
\hline King Abdulaziz University & 5.3 & 53 & 2.04 \\
\hline Majmaah University & 1.3 & 23 & 1.5 \\
\hline Harvard University & 11.3 & 2.6 & 2.4 \\
\hline $\begin{array}{c}\text { Massachusetts Institute of } \\
\text { Technology }\end{array}$ & 9.4 & 1.4 & 2.6 \\
\hline
\end{tabular}

Behind the desire to rank highly, healthy academic-corporate collaborations lie in the fact that there are numerous challenges to be solved in the modern world, whether science, new technology, medicine, and other areas. Previously, it was common for universities to solicit sponsored scholarships and corporate donations from the private sector in a piecemeal manner, project by project, and researcher by a researcher [22]. Corporations would also contract research work to help with licensing patents and other processes. While the model posed minimal risk for all parties involved, it was limited in scope. The increasing demand of knowledge present today requires that two sectors expand on their collaboration [23]. The transaction model for new long-term partnerships required that students develop research gaps and gain tangible-world experiences while the industry gains insights through programs. Collaborative programs provide students with the chance to form the advancement of fields to get first -hand experience at processes and gain significant knowledge and experience that employers pursue in employees. Public and private enterprises gain access to some of the great minds in any subject area and access to new talents, sharing project costs with institutions and use the institution's cutting resources [24]. Companies fund or co-fund postdoctoral researchers or Ph.D. candidates are studying difficult scientific areas and other areas of interest to companies such as information technology. When something promising emerges, more funding is obtained either through a collaborative proposal to a government agency by companies and universities or directly from the company.

\section{The quality control factor}

The universities have a mission to contribute to society through the pursuit of research that meets the world's levels of excellence. Quality is reflected in the core values of the university across all subjects. The university's quality assurance procedures provide a framework within which its institution can examine and enhance its education to enable it to achieve the aspiration of excellence [25]. The university is accountable for the standards and quality of its provision and is expected to have quality control measures and adhere to regulatory, statutory, and professional bodies.

In the area of research, Majmaah University has instituted resources, systems, and techniques to give assurance about the control with which research is carried out [26]. There is a specific department within the institution that is concerned with the handling of samples and materials, methods research records, equipment documentation of procedures, the competence of research staff facilities, and project planning [27]. The university code of good research practices lays out principles and practices of good research and applies to parties who conduct research at the university, including students and faculties. The consideration is given to the fact that the university's quality assurance procedures should be driven by external quality regimes [28]. Majmaah University has major obligation for the quality of its establishment and its assurance. As such, the external quality assurance needs should be taken into account and support the development of good internal quality assurance within the university. The quality assurance measures instituted in the university respond to the diversity of higher education programs, institutions, and systems as well as students. There is full ownership of the quality assurance process to reduce the bureaucracy that characterizes such exercises.

The ABET has accredited programs in the institution. The process is voluntary [29]. National Commission for Academic Accreditation and Assessment (NCAAA) is also an accreditation form established in the Saudi Arabia. It determines the criteria and standards for academic accreditation and assessment for accrediting higher learning institutions and the programs offered at those institutions. The university accreditation is considered to be an indicator of quality. However, there are controversies as to whether rankings measure or indicate higher education quality comprehensively and fairly. The publicity and simplicity of ranking have served the general purpose of putting international and public attention on the importance and role of higher education to individuals and societies that have underpinned the necessity of adequate investment in higher education. The faculty of Majmaah University performs an essential role in achieving the objectives of attaining excellence. Making and maintaining high quality is not an easy task. The cooperation between the faculty and departments is essential in achieving long-term strategic initiatives.

\section{Analysis of benchmarking institutional universities}

\section{The research results}

The section presents an overall metrics summary of Majmaah University. It also gives an overview of the research areas in which the university is publishing based on the high level All Science Journal Classification (ASJC). All articles are assigned specific subject areas according to the criteria used by the journals in which each is published. One article can be published in several journals. Figure 3 shows the publication output and Harvard University is the leading during this present study from 2015 to 2019 . The number of publications is one of the key or indicators for increasing the university ranking.

\section{The economic \& social results}

The economics and social results of the publishing sector influence the dissemination of research findings. Majmaah University understands its role in contributing to the economy of the city and Saudi Arabia as a whole as well as society. The institution offers

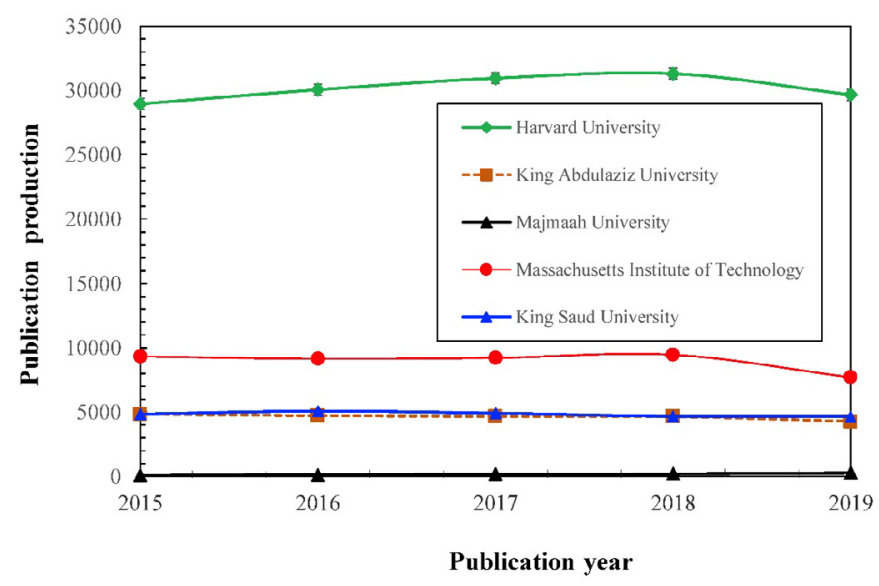

Figure 3. Benchmarking institutional universities of the publication year and scholarly production 
extension courses for the local communities and social amenities. Additionally, the institution makes an important contribution through the development of researchers who proceed to make an impact in their areas of knowledge within the modern global economy. Majmaah University provides students with a range of programs aimed at preparing learners for diverse economic sectors, thus helping them to succeed and grow in the labor market while keeping pace with changes in the innovation process and changes in the global economy. The university also promotes lifelong learning by developing professionals in industries through training and research opportunities.

\section{The Academic-corporate collaboration result}

Majmaah University is engaged in a range of collaboration with the corporate region. Saudi Arabia has several physical resources, which incorporate natural gas, petroleum, $\mathrm{Au}, \mathrm{Fe}$, and $\mathrm{Cu}$. Major industries include basic petrochemicals, petroleum refining, natural gas production, industries such as crude oil, plastic, fertilizer, construction, steel-rolling mills, and cement. Majmaah University plays a significant role in research activities and consultations actions as practical in regional industries. In fact, Majmaah University considers the industry as a significant element of its outer constituents. One of the goals of the engineering college demonstrates the institutions focus on partnering with the industry. Over the years, the university's association with industry has built to full-fledged collaborations. Some forms of collaboration involve consultation, research, grants and rewards, training, and industrial consultative formation committees.

In the area of consultation, teaching staff members in the university provide consultation to different industries. Some teaching staff members work as part-time advisors and full-time consultants in various firms in industries. In the area of research, the university has a strong and well-thought outreach program with the society, government, and industry that have led to the financial sponsoring of many research activities, including research centers. In the area of scholarships and rewards, the university receives support from the industry in different educational aspects in the university through the establishment of scholarships to high performing students in different the institution departments. Awards are also given to outstanding graduation projects in various departments. Scholarships given include monthly salary, the possibility of employment, and training.

Collaboration in the area of training is achieved through two major ways. The first way entails engaging in summer training programs in industry companies or government institutions. Summer training programs are a requirement for graduation. The second way is through specialized training received from the university. The institution provides training in diverse fields to professionals working in industries. Professionals in the industry can take advantage of laboratories and facilities in the university during their training - Industrial Advisory Committees comprised of individuals in the institution and those in the industry. The integrated relationship between the institution and industry players is cultivated during advisory committee meetings and functions. Members of the committee may also be selected from government bodies (Figure 4).

\section{The quality control results}

The ABET team evaluated the bachelor programs at CCIS in IT program (network management, multimedia \& web design and digital forensics) and computer science (software engineering and computer security) in 2018. The evaluation involved the assessment of professional development, learning outcomes, administrative competences, faculty

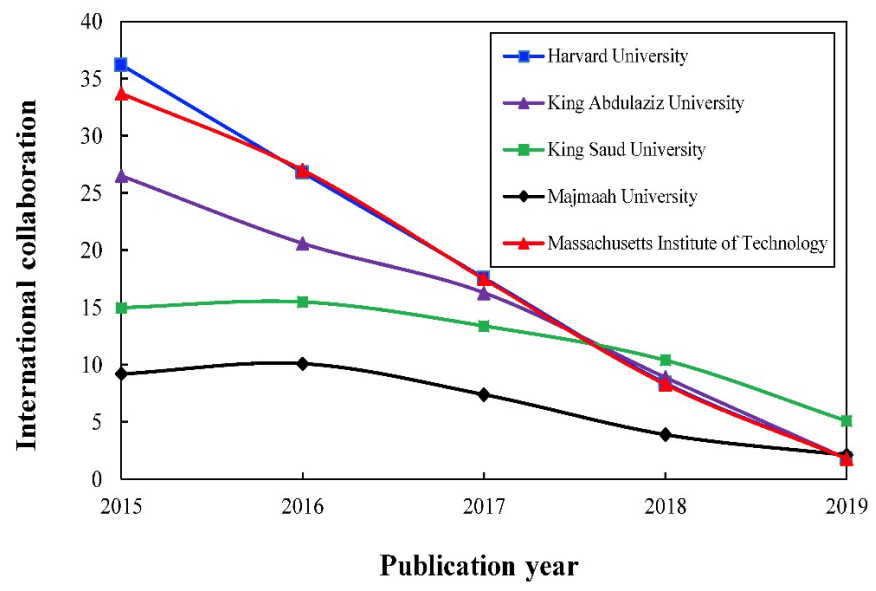

Figure 4. Benchmarking institutional universities of the publication year and international collaboration

qualification, research, facilities, labs, and study plans [30]. The report shows that the university's CCIS programs fulfill all the criteria of ABET accreditation in addition to preparing students for the job market, professional partnerships with new technology companies, and quality of tracks and labs [31]. The process of ABET Accreditation is conducted by several accreditation commissions, such as for specific degree levels and program areas [32]. Majmaah University ranks position 23 and 4956 in the world rank, according to the National Commission for Academic Accreditation and Assessment (NCAAA) [33]. The university also has campuses officially accredited by the several locations such in Rumah, Ghat, Hutah, and Zulfi.

\section{Conclusions}

The results show that Majmaah University has made efforts to increase citations and visibility of academic publications. The institution is continually feeding their data into areas that are underrepresented in the relevant databases such as engineering that traditionally favor book publications as compared to journal articles. Majmaah University is engaged in a range of collaboration with the corporate sector in areas such as consultation, research, scholarships and contributions, workshops, and the industrial advisory formation committees. In the area of session, faculty members in the university provide consultation to different industries. In the area of research, the university has a strong and well-thought outreach program with the society, government, and industry that have led to the financial sponsoring of many research activities, including research centers. In the area of scholarships and rewards, the university receives support from the industry in different educational characteristics in the university over the requirement of scholarships to high performing students in different departments of the institution. Collaboration in training is done through students' summer training programs in industry companies or government institutions and training of professionals in diverse fields in industries. The institution offers extension courses for the local communities and social amenities and makes an important contribution through the development of researchers who proceed to make an impact in their areas of knowledge within the modern global economy. The report shows that the university's CCIS programs fulfill all the criteria of ABET accreditation in addition to preparing students for the job market, professional partnerships with new technology companies, and the quality of tracks and labs. Majmaah University ranks position 23 and 4956 in world rank by National Commission for Academic Accreditation and Assessment. Compared to King Saud University 
and King Abdulaziz University, Harvard University and Massachusetts University, Majmaah University ranks low in research institutional ranking. In the world rank, King Saud University, King Abdulaziz University, and King Abdulla University of Science \& Technology rank 451, 437, and 494, respectively. Over 63 Universities in Saudi Arabia are included in the rank. Majmaah University ranks 4782 in the world ranking and 22nd among Saudi Arabia Universities.

\section{Acknowledgments}

The author gratefully acknowledges the Engineering and Applied Science Research Center at Majmaah University for the technical support of the present study. Also, the authors extend their appreciation to the Deanship of Scientific Research at Majmaah University for funding this work.

\section{References}

1. Daraio C, Bonaccorsi A, Simar L (2015) Rankings and university performance: A conditional multidimensional approach. European Journal of Operational Research 244: 918-930.

2. Millot B (2015) International rankings: Universities vs. higher education systems. International Journal of Educational Development 40: 156-165.

3. O'leary J (2019) Classifying higher education institutions in the MENA region. Available at: https://www.qs.com/classifying-higher-education-institutions-in-themena-region/.

4. Douglass JA (Ed.) (2016) The new flagship university: Changing the paradigm from global ranking to national relevancy. Springer.

5. Webometrics (2019) Ranking of web universities. Saudi Arabia. Available at: https:// www.webometrics.info/en/Asia/Saudi\%20Arabia\%20.

6. Hazelkorn E (2015) Rankings and the reshaping of higher education: The battle for world-class excellence. Springer.

7. Vernon MM, Balas EA, Momani S (2018) Are university rankings useful to improve research? A systematic review. Plos One 13: e0193762.

8. Moed HF (2017) A critical comparative analysis of five world university rankings. Scientometrics 110: 967-990.

9. Christy RD (2017) A century of service: Land-grant colleges and universities, 18901990. Routledge.

10. Majmaah University (2018) ABET Fulfills CCIS Programs Evaluation. Available at https://m.mu.edu.sa/en/news/computer-sciences-and-information-technology-college/ abet-fulfills-ccis-programs-evaluation.

11. Ware M, Mabe M (2015) The STM report: An overview of scientific and scholarly journal publishing.

12. Ordorika I, Lloyd, M (2015) International rankings and the contest for university hegemony. Journal of Education Policy 30: 385-405.

13. Tijssen RJ, Yegros-Yegros A, Winnink JJ (2016) University-industry R\&D linkage metrics: validity and applicability in world university rankings. Scientometrics 109 : 677-696.
14. Chambers CD, Dienes Z, McIntosh RD, Rotshtein P, Willmes K (2015) Registered reports: realigning incentives in scientific publishing. Cortex 66: A1-A2.

15. Teixeira da Silva JA, Dobránszki J (2015) Problems with traditional science publishing and finding a wider niche for post-publication peer review. Accountability in Research 22: $22-40$.

16. Guerrero M, Cunningham JA, Urbano D (2015) Economic impact of entrepreneurial universities' activities: An exploratory study of the United Kingdom. Research Policy 44: 748-764.

17. Çakır MP, Acartürk C, Alaşehir O, Çilingir C (2015) A comparative analysis of global and national university ranking systems. Scientometrics 103: 813-848.

18. Lesley P (2018) The University Challenge (2004): Higher Education Markets and Social Stratification. Routledge.

19. Porter J, Morgan J, Lester R, Steele A, Vanegas J, et al. (2015) A course in innovative product design: A collaboration between architecture, business, and engineering. IEEE Frontiers in Education Conference.

20. Chi CL, Wang J (2017) Case Study 9.1: Academic/corporate partnerships: Development of a model to predict adverse events in patients prescribed statins using the Optumlabs data warehouse. Big Data-Enabled Nursing: Education, Research and Practice.

21. Garber R (2017) Academic-corporate engagement: Strategic and organizational best practices. Research Management Review 22.

22. Zhou K, Liu T, Zhou L (2015) Industry 4.0: Towards future industrial opportunities and challenges. 12th International conference on fuzzy systems and knowledge discovery (FSKD).

23. Shneiderman B (2016) The new ABCs of research: Achieving breakthrough collaborations. Oxford University Press.

24. Crown W, Clancy TR (2017) Working in the new big data world: Academic/corporate partnership model. Big Data-Enabled Nursing.

25. Abdeljaber HAM, Ahmad S (2017) Program outcomes assessment method for multiacademic accreditation bodies: Computer science program as a case study. International Journal of Emerging Technologies in Learning 12: 23-35.

26. Brahimi T, Sarirete A, Khalifa S (2018) Impact of accreditation on engineering education. Enhancing Knowledge Discovery and Innovation in the Digital Era.

27. Griego RM (2017) Perspectives on abet accreditation of systems engineering programs (No. SAND2017-6811C). Sandia National Lab (SNL-NM). Albuquerque, NM (United States)

28. Taleb A, Namoun A, Benaida M (2016) A holistic quality assurance framework to acquire national and international accreditation: The case of Saudi Arabia.

29. ABET (2019) Accreditation. Available at https://www.abet.org/accreditation/.

30. Alarifi IM, Alharbi A, Alsaiari O, Asmatulu R (2015) Training the engineering students on nanofiber-based SHM systems. Transactions on Techniques in STEM Education 1: 59-67.

31. Majmaah University (2019) Research groups. Available at https://m.mu.edu.sa/en/ colleges/college-science-al-zulfi/research-groups-2.

32. Almutairi M (2017) A comparative study of ABET accredited associate degree programs, evidence from Saudi Arabia. Business Education \& Accreditation 8: 65-81.

33. UNIRANK (2019) Majmaah University. Available at https://www.4icu.org/ reviews/13870.htm.

Copyright: $\odot 2020$ Alarif IM. This is an open-access article distributed under the terms of the Creative Commons Attribution License, which permits unrestricted use, distribution, and reproduction in any medium, provided the original author and source are credited. 